\title{
Most Corynebacterium xerosis Strains Identified in the Routine Clinical Laboratory Correspond to Corynebacterium amycolatum
}

\author{
GUIDO FUNKE, ${ }^{1 *}$ PAUL A. LAWSON,${ }^{2}$ KATHRYN A. BERNARD,${ }^{3}$ AND MATTHEW D. COLLINS ${ }^{2}$ \\ Department of Medical Microbiology, University of Zürich, CH-8028 Zürich, Switzerland ${ }^{1}$; Department of \\ Microbiology, BBSRC Institute of Food Research, Reading Laboratory, Reading RG6 6BZ, United Kingdom ${ }^{2}$; and \\ Special Bacteriology Laboratory, Laboratory Centre for Disease Control, Ottawa, Ontario K1A OL2, Canada ${ }^{3}$
}

Received 28 November 1995/Returned for modification 22 January 1996/Accepted 2 February 1996

\begin{abstract}
A comprehensive study was performed on 25 bacterial clinical isolates originally identified as Corynebacterium xerosis. Three reference strains of $C$. xerosis were also included in the study. On the basis of a variety of phenotypic characteristics tested, all strains could be divided into two separate clusters: reference strains ATCC 373 (the type strain of $C$. xerosis) and ATCC 7711 showed yellow-pigmented, dry, rough colonies, fermented 5-keto-gluconate, exhibited strong leucine arylamidase and $\alpha$-glucosidase activities, produced lactate as the major end product of glucose metabolism, were susceptible to most of the 19 antimicrobial agents tested, and showed an inhibition zone around disks containing the vibriocidal compound $0 / 129$. In contrast, the remaining 26 strains including reference strain NCTC 7243 as well as all clinical isolates formed whitegrayish, dry, slightly rough colonies, did not ferment 5-keto-gluconate, exhibited only weak leucine arylamidase and no $\alpha$-glucosidase activity, produced large amounts of propionic acid as the end product of glucose metabolism, and were resistant to most antimicrobial agents tested, including $\mathrm{O} / 129$. Chemotaxonomic (cellular fatty acids, mycolic acids, and $G+C$ content) and molecular genetic (16S rRNA gene sequence) investigations revealed that the strains of the second cluster unambiguously belonged to the species $C$. amycolatum. Our data suggest that most strains reported in the literature as $C$. xerosis are probably misidentified and correspond to $C$. amycolatum.
\end{abstract}

Within the last few years numerous publications have focused on the disease associations of coryneform bacteria as well as on the taxonomy of this heterogeneous group of bacteria. The reason for this is that clinical microbiologists and clinicians have become more and more aware of the pathogenic potential of coryneform bacteria, especially in immunocompromised patients. In recent years, one of the most frequently reported coryneform bacteria causing infections in humans has been Corynebacterium xerosis $(2,13,16,18,19$, 26-28). On the other hand, there are some reports of the heterogeneity of what was generally thought to be $C$. xerosis (6). The most recent and valuable study came from Coyle and coworkers (7), who demonstrated multiple taxa within commercially available reference strains of $C$. xerosis. In order to clarify the identity of $C$. xerosis strains isolated from clinical specimens, 25 strains originally identified as C. xerosis and referred to two reference laboratories in Europe and North America for identification were studied by applying phenotypic as well as molecular genetic methods. Three reference strains of $C$. xerosis were also included in the study for comparative investigations. Some lipophilic strains available as $C$. xerosis reference strains (7) were not included in the present investigations since a recent study demonstrated that these strains actually belong to some other already established taxa (17). $C$. xerosis strains were identified according to the Hollis-Weaver guide for the identification of gram-positive bacteria (14) and not according to the criteria given in Bergey's manual (6); i.e., C. xerosis strains produced acid from maltose. Most surprisingly, all 25 clinical strains examined turned out to be $C$. amycolatum. Therefore, our observations cast doubt on the iden-

* Corresponding author. Mailing address: Department of Medical Microbiology, University of Zürich, Gloriastr. 32, CH-8028 Zürich, Switzerland. Phone: 41-1-257-2700. Fax: 41-1-252-8107. tities of most strains of so-called $C$. xerosis reported in the literature.

\section{MATERIALS AND METHODS}

Strains, media, and growth conditions. The strains studied are listed in Table 1. The reference strains used for comparative investigations were obtained from the American Type Culture Collection (ATCC; Rockville, Md.) and the National Collection of Type Cultures (NCTC; London, United Kingdom). The other strains were referred to the Department of Medical Microbiology (DMMZ), University of Zürich, Zürich, Switzerland, and the Special Bacteriology Laboratory, Laboratory Centre for Disease Control (LCDC), Ottawa, Ontario, Canada, between 1989 and 1995. For examination of the CAMP reaction, Staphylococcus aureus ATCC 25923 was used. All strains were cultured on Columbia agar (Difco, Detroit, Mich.) with $5 \%$ sheep blood (SBA) at $37^{\circ} \mathrm{C}$ in a $5 \% \mathrm{CO}_{2}$ atmosphere.

Biochemical tests. Preparation of the media used for biochemical characterization of the strains was done as described by Nash and Krenz (20). All biochemical tests were carried out at $37^{\circ} \mathrm{C}$. Testing of the other biochemical characteristics given in Table 2 has been outlined in detail previously $(11,12)$ Hydrolysis of starch was tested on Mueller-Hinton agar plates after $48 \mathrm{~h}$ of incubation by flooding the plates with a 1:5 dilution of Lugol's iodine solution. The commercial API (RAPID) Coryne system was used as recommended by the manufacturer (API bioMérieux, Marcy l'Etoile, France); readings of the carbohydrate fermentation reactions were done after 24 and $48 \mathrm{~h}$ of incubation. The activities of leucine arylamidase and $\alpha$-glucosidase were tested (apart from examination with the API Zym and the API Coryne systems) with Rosco tablets (Rosco, Taastrup, Denmark) by preparing a bacterial suspension with turbidity equivalent to that of a McFarland no. 3 standard and incubation for $18 \mathrm{~h}$ as recommended by the manufacturer.

Antimicrobial susceptibility patterns. The susceptibilities of the 28 strains included in the present study to 19 antimicrobial agents known to have activity against coryneform bacteria were tested according to the guidelines for performance and interpretation of the National Committee for Clinical Laboratory Standards $(21,22)$. For interpretation of susceptibility to amoxicillin-clavulanic acid, ampicillin, oxacillin, and penicillin, the categories for staphylococci were used. MICs were tested by the agar dilution procedure (Mueller-Hinton agar supplemented with $5 \%$ sheep blood). For susceptibility to the vibriocidal compound $\mathrm{O} / 129$, disks with $150 \mu \mathrm{g}$ of O/129 (Oxoid, Basingstoke, United Kingdom) were placed on Mueller-Hinton agar supplemented with 5\% sheep blood after streaking the plates with a suspension with turbidity equivalent to that of a McFarland no. 0.5 standard. Growth inhibition zones were observed after $24 \mathrm{~h}$ of incubation at $37^{\circ} \mathrm{C}$. 
TABLE 1. Strains included in the study

\begin{tabular}{lll}
\hline \multicolumn{1}{c}{ Strain group and no. } & $\begin{array}{c}\text { Yr of } \\
\text { isolation }\end{array}$ & \\
\hline C. xerosis & & \multicolumn{1}{c}{ Source } \\
ATCC 373 (type strain) & 1924 & Ear discharge \\
ATCC 7711 & 1940 & NK $^{a}$ \\
& & \\
C. amycolatum primarily & & \\
misidentified as C. xerosis & & \\
NCTC 7243 & 1947 & Infant nose \\
DMMZ 103 & 1991 & Blood culture \\
DMMZ 323 & 1992 & Blood culture \\
DMMZ 1171 & 1994 & Intravascular catheter \\
DMMZ 1303 & 1993 & Deep wound, lower leg \\
DMMZ 1318 & 1994 & Easy flow secretion \\
DMMZ 1373 & NK & Urine \\
DMMZ 1422 & 1995 & Retroauricular fistula \\
DMMZ 1423 & 1995 & Fistula, upper leg \\
DMMZ 1480 & 1995 & Deep wound, lower leg \\
DMMZ 1502 & 1995 & Blood culture \\
DMMZ 1503 & 1995 & Blood culture \\
DMMZ 1525 & 1995 & Intravascular catheter \\
DMMZ 1528 & 1995 & Intravascular catheter \\
DMMZ 1532 & 1995 & Intravascular catheter \\
DMMZ 1563 & 1995 & Abscess \\
DMMZ 1566 & 1995 & Perianal abscess \\
DMMZ 1618 & 1995 & Urine \\
DMMZ 1624 & 1995 & Intravascular catheter \\
DMMZ 1668 & 1995 & Intravascular catheter \\
DMMZ 1680 & 1995 & Intravascular catheter \\
DMMZ 1788 & 1995 & Blood culture \\
LCDC 89-0826 & 1989 & Back wound \\
LCDC 91-0077 & 1991 & Sternal bone fragments \\
LCDC 92-0042 & 1992 & Aspirate from shoulder \\
LCDC 92-0043 & 1992 & Blood culture \\
\hline
\end{tabular}

${ }^{a}$ NK, not known; the strain was originally from the University of Maryland and was deposited in ATCC

${ }^{b} \mathrm{NK}$, year not known.

Gas-liquid chromatography. Determination of volatile and nonvolatile fatty acids from the fermentation of glucose was performed as described previously (11). For analysis of cellular fatty acids, cells were grown on Columbia agar base (Oxoid) supplemented with $5 \%$ defibrinated sheep blood at $35^{\circ} \mathrm{C}$ for $24 \mathrm{~h}$ in a $5 \%$ $\mathrm{CO}_{2}$ incubator. Fatty acid derivatization and gas-liquid chromatography of the cellular fatty acids were done as outlined before (4), except that we used MIDI software, version 3.8 .

Chemotaxonomic investigations. For the detection of the diamino acid of the cell wall peptidoglycan and of the presence of mycolic acids, the methods outlined by Schaal (24) were applied. Cell wall components were separated by thin-layer chromatography and were then visualized. The method for determination of the $\mathrm{G}+\mathrm{C}$ contents of the bacterial DNAs was as given in an earlier report (12).

16S rRNA gene sequence analysis. A large fragment of the 16S rRNA gene was amplified from DNA by PCR with universal primers pA (positions 8 to 28; Escherichia coli numbering) and $\mathrm{pH}$ (positions 1542 to 1522). The amplified product was sequenced directly by using primers to conserved regions of the rRNA. Sequencing was performed with a PRISM Dyedeoxy Terminator Cycle Sequencing Kit (Applied Biosystems, Warrington, United Kingdom), and the reaction products were electrophoresed with an Applied Biosystems model 373A automatic DNA sequencer according to the manufacturer's protocols (Applied Biosystems). Sequences were compared by pairwise analysis (9).

\section{RESULTS}

Thirteen of the 25 clinical strains were isolated from blood cultures or from intravascular catheters. Many other strains came from infections which were anatomically closely related to the skin. Two cases of urinary tract infections were noted, but none of the clinical strains originated from a respiratory tract specimen.

Macroscopic morphology separated all strains examined
TABLE 2. Biochemical characteristics of the strains studied

\begin{tabular}{|c|c|c|c|}
\hline \multirow{2}{*}{ Reaction } & \multicolumn{2}{|c|}{$\begin{array}{c}\text { Result for } C \text {. } \\
\text { xerosis }(n=2)\end{array}$} & \multirow{2}{*}{$\begin{array}{l}\text { \% Positive reactions } \\
\text { for C. amycolatum } \\
\quad(n=26)\end{array}$} \\
\hline & $\begin{array}{c}\text { ATCC } \\
373\end{array}$ & $\begin{array}{c}\text { ATCC } \\
7711\end{array}$ & \\
\hline Catalase & + & + & 100 \\
\hline Motility & - & - & 0 \\
\hline Nitrate reduction & + & - & 96 \\
\hline \multicolumn{4}{|l|}{ Hydrolysis of } \\
\hline Urea & - & - & 0 \\
\hline Esculin & - & - & 0 \\
\hline Gelatin & - & - & 0 \\
\hline Starch & + & $(+)^{a}$ & 100 \\
\hline Casein & - & - & 0 \\
\hline Tyrosine & - & - & 0 \\
\hline Xanthine & - & - & 0 \\
\hline CAMP reaction & - & - & 0 \\
\hline \multicolumn{4}{|l|}{ Fermentation of ${ }^{b}$ : } \\
\hline Glucose & + & + & 100 \\
\hline Maltose & + & + & 100 \\
\hline Sucrose & + & + & 100 \\
\hline Mannitol & - & - & 0 \\
\hline Xylose & - & - & 0 \\
\hline Ribose & + & + & 92 \\
\hline Lactose & - & - & 0 \\
\hline Glygogen & - & - & 0 \\
\hline 5-Keto-gluconate & + & + & 0 \\
\hline \multicolumn{4}{|l|}{ Activity of ${ }^{c}$ : } \\
\hline Pyrazinamidase ${ }^{d}$ & + & + & 100 \\
\hline Pyrrolidonyl arylamidase ${ }^{d}$ & - & - & 0 \\
\hline Alkaline phosphatase & $+(w)$ & $+(w)$ & $100(\mathrm{~s})$ \\
\hline Esterase $\left(\mathrm{C}_{4}\right)$ & $+(\mathrm{m})$ & $+(\mathrm{m})$ & $100(\mathrm{~m})$ \\
\hline Esterase lipase $\left(\mathrm{C}_{8}\right)$ & $+(s)$ & $+(s)$ & $100(\mathrm{~s})$ \\
\hline Lipase $\left(C_{14}\right)$ & - & $+(\mathrm{w})$ & $92(w)$ \\
\hline Leucine arylamidase & $+(\mathrm{s})$ & $+(\mathrm{s})$ & $85(\mathrm{w})$ \\
\hline Valine arylamidase & - & - & 0 \\
\hline Cystine arylamidase & $+(\mathrm{w})$ & $+(w)$ & $100(w)$ \\
\hline Trypsin & - & - & 0 \\
\hline Chymotrypsin & - & - & 0 \\
\hline Acid phosphatase & $+(w)$ & $+(w)$ & $100(w)$ \\
\hline Phosphoamidase & $+(\mathrm{w})$ & $+(\mathrm{w})$ & $92(w)$ \\
\hline$\alpha$-Galactosidase & - & - & 0 \\
\hline$\beta$-Galactosidase & - & - & 0 \\
\hline$\beta$-Glucuronidase & - & - & 0 \\
\hline$\alpha$-Glucosidase & $+(\mathrm{s})$ & $+(s)$ & 0 \\
\hline$\beta$-Glucosidase & - & - & 0 \\
\hline$n$-Acetyl- $\beta$-glucosaminidase & - & - & 0 \\
\hline$\alpha$-Mannosidase & - & - & 0 \\
\hline$\alpha$-Fucosidase & - & - & 0 \\
\hline
\end{tabular}

${ }^{a}$ Parentheses indicate weak activity only.

${ }^{b}$ All fermentation reactions except for that for 5-keto-gluconate were determined at $48 \mathrm{~h}$ of incubation; the reaction for 5-keto-gluconate was recorded at $120 \mathrm{~h}$.

${ }^{c}$ As measured with the API Zym system. (w), approximately $5 \mathrm{nmol}$ of substrate hydrolyzed; (m), approximately $20 \mathrm{nmol}$ of substrate hydrolyzed; (s), $>40$ nmol of substrate hydrolyzed.

${ }^{d}$ As measured with the API Coryne system.

into two groups (Table 1): all clinical strains grew as whitegrayish, dry, slightly rough colonies of 1 to $2 \mathrm{~mm}$ in diameter after 48 h of incubation; these strains were referred to as $C$. xerosis-like (later shown to be $C$. amycolatum) strains. The other group (referred to as the $C$. xerosis group) contained the 
type strain of $C$. xerosis (ATCC 373) and reference strain ATCC 7711 only. These two strains showed yellow-pigmented (after $48 \mathrm{~h}$ of incubation on SBA at $37^{\circ} \mathrm{C}$ ), dry, and rough colonies reminiscent of rapidly growing mycobacteria. Microscopically, no differences were observed between the two groups of strains since both showed typical club-shaped, nonpartially acid-fast, gram-positive organisms, as observed for Corynebacterium spp. in general.

None of the key reactions usually applied in the routine identification of coryneform bacteria (nitrate reduction, urea hydrolysis, esculin hydrolysis, fermentation of glucose, maltose, sucrose, mannitol, and xylose, and the CAMP test) were found to differentiate the two groups of bacteria (Table 2). It should be noted that reference strains ATCC 7711 and NCTC 7243 were unable to reduce nitrate (as also reported by others [7]), whereas all other strains reduced nitrate. When applying the API (RAPID) Coryne system, we observed that both strains of the $C$. xerosis group exhibited strong $\alpha$-glucosidase activity which was not present in strains of the C.xerosis-like group. This difference was confirmed by testing $\alpha$-glucosidase activity with the API Zym gallery as well as with Rosco tablets. Furthermore, we found that in the 26 strains of the $C$. xerosislike cluster, leucine arylamidase activity was absent or only weak, whereas the other two strains showed very strong activity of this enzyme. In addition, the testing of all 28 strains included in the present study with the API Zym system indicated stronger activity of alkaline phosphatase in the strains of the $C$. xerosis-like cluster than in the two other strains. The API 50 $\mathrm{CH}$ system did not provide further differential reactions between the two groups of organisms except that the two strains of the C.xerosis group produced acid from 5-keto-gluconate, which was not observed for any strain of the other group. All C. xerosis-like strains produced large amounts of propionic acid, whereas the two other strains produced lactate as their major end product of the glucose metabolism.

Table 3 outlines the different API (RAPID) Coryne profiles and identifications for all 28 strains tested after 24 and $48 \mathrm{~h}$ of incubation. It should be noted that 24 and 25 of 26 C. xerosislike strains were identified with very good scores as $C$. xerosis after 24 and $48 \mathrm{~h}$ of incubation, respectively.

The majority of the C. xerosis-like strains were multiresistant, as revealed by the MICs at which $50 \%\left(\mathrm{MIC}_{50} \mathrm{~s}\right)$ and $90 \%$ $\left(\mathrm{MIC}_{90} \mathrm{~s}\right)$ of strains are inhibited (Table 4). Tetracycline, teicoplanin, and vancomycin were the only antimicrobial agents whose $\mathrm{MIC}_{90} \mathrm{~s}$ were below the breakpoints recommended by the National Committee for Clinical Laboratory Standards (22). In contrast, the two strains of the C. xerosis group were susceptible to nearly all antimicrobial agents tested. Another easy-to-perform test which clearly separated the two groups was the resistance of all $C$. xerosis-like strains to the vibriocidal compound $\mathrm{O} / 129$; both strains of the $C$. xerosis group showed inhibition zones.

Cellular fatty acid analysis revealed qualitatively similar patterns for both $C$. xerosis and C. xerosis-like strains (Table 5). However, quantitative differences in the cellular fatty acid patterns were noted, with significantly lower amounts of palmitic acid but higher amounts of oleic acid in C. xerosis strains compared with the amounts in the $C$. xerosis-like strains. In the analyses of $C$. xerosis strains, not all resulting peaks could be assigned to certain cellular fatty acids. These unidentifiable peaks (at or near equivalent chain lengths 15.000, 16.8, and 17.000) represented cleaved mycolic acids. In contrast, no peaks suggestive of cleaved mycolic acids were detected in the C. xerosis-like strains.

All 28 strains studied contained meso-diaminopimelic acid in their peptidoglycan. In both $C$. xerosis strains, mycolic acids
TABLE 3. API Coryne profiles of the strains studied

\begin{tabular}{|c|c|c|c|c|}
\hline \multirow{2}{*}{$\begin{array}{l}\text { Incubation time, strain, } \\
\text { and numerical code } \\
\text { (no. of strains) }\end{array}$} & \multicolumn{4}{|c|}{ Results by the API Coryne system } \\
\hline & Identification & $\begin{array}{c}\% \\
\text { Identified }^{a}\end{array}$ & $\begin{array}{c}\mathrm{T} \\
\text { index }\end{array}$ & $\begin{array}{c}\text { Profile } \\
\text { acceptance }\end{array}$ \\
\hline \multicolumn{5}{|l|}{$24 \mathrm{~h}$} \\
\hline \multicolumn{5}{|l|}{ C. xerosis $(n=2)$} \\
\hline \multirow[t]{2}{*}{$\begin{array}{l}2110305 \\
\text { (ATCC 7711) }\end{array}$} & $\begin{array}{r}\text { Corynebacterium } \\
\text { sp. strain G-2 }\end{array}$ & 71.8 & 0.43 & Doubtful \\
\hline & C. striatum & 23.3 & 0.35 & \\
\hline $\begin{array}{l}3110325 \\
\text { (ATCC 373) }\end{array}$ & C. xerosis & 99.8 & 0.77 & Very good \\
\hline \multicolumn{5}{|l|}{$\begin{array}{c}\text { C. amycolatum } \\
(n=26)\end{array}$} \\
\hline $\begin{array}{l}2100125 \\
\text { (NCTC 7243) }\end{array}$ & C. minutissimum & 97.1 & 0.92 & Good \\
\hline $3100105(1)$ & C. striatum & 97.1 & 1.00 & Good \\
\hline 3100125 (14) & C. xerosis & 99.7 & 0.95 & Very good \\
\hline $3100325(10)$ & C. xerosis & 99.6 & 1.00 & Very good \\
\hline
\end{tabular}

$48 \mathrm{~h}$

C. xerosis $(n=2)$

2110325
(ATCC 7711)

C. minutissimum $\quad 53.2 \quad 0.50$ Doubtful

(ATCC 7711)

C. xerosis

46.7

0.49

3110325

C. xerosis

99.8

0.77 Very good

(ATCC 373)

C. amycolatum

$(n=26)$

2100325

C. minutissimum

97.9

1.00 Good

(NCTC 7243)

3100125 (2)

C. xerosis

3100325 (23) $\quad$ C. xerosis

$99.7 \quad 0.95 \quad$ Very good

$99.6 \quad 1.00 \quad$ Very good

${ }^{a}$ Identification percentages of less than 3.0 were not reported.

could be detected, but in the $C$.xerosis-like strains, no mycolic acids were found, even after repeated attempts. The only species within the genus Corynebacterium not containing mycolic acids is $C$. amycolatum $(5,6,23)$. Determination of the $\mathrm{G}+\mathrm{C}$ contents of the two C. xerosis strains revealed values of 66 to 69 mol\%; in contrast, the C. xerosis-like strains possessed significantly lower amounts of $\mathrm{G}+\mathrm{C}$ (55 to $60 \mathrm{~mol} \%$ ).

To further investigate the possible affinity between $C$. xerosis-like strains and C. amycolatum, phylogenetic analyses were performed. A large fragment of the $16 \mathrm{~S}$ rRNA genes of five representative clinical isolates (strains DMMZ 323, DMMZ 1171, DMMZ 1303, DMMZ 1318, and DMMZ 1422) and strain NCTC 7243 was amplified by PCR and sequenced. Approximately 1,400 bases were determined for each strain, and pairwise analyses showed the six strains to be highly related to each other and to the type strain of $C$. amycolatum (strain NCFB 2768 [5]). Considerably lower sequence relatedness $(<98 \%)$ was shared with $C$. xerosis ATCC 373, to which the 16S rRNA gene sequence of reference strain ATCC 7711 was identical. These findings demonstrate that the $C$. xerosis-like group of strains do not correspond to $C$. xerosis but are representatives of the species $C$. amycolatum.

\section{DISCUSSION}

Phenotypic, chemotaxonomic, and molecular genetic investigations revealed that none of the 25 clinical isolates studied 
TABLE 4. Antimicrobial susceptibility patterns of the strains studied ${ }^{a}$

\begin{tabular}{|c|c|c|c|c|c|}
\hline \multirow{3}{*}{ Substance } & \multicolumn{5}{|c|}{$\operatorname{MIC}(\mu \mathrm{g} / \mathrm{ml})$} \\
\hline & \multicolumn{2}{|c|}{ C. xerosis $(n=2)$} & \multicolumn{3}{|c|}{ C. amycolatum $(n=26)$} \\
\hline & ATCC 373 & ATCC 7711 & Range & $50 \%$ & $90 \%$ \\
\hline Amoxicillin-clavulanic acid & $\leq 0.03$ & 0.06 & $0.13->64$ & 1 & 64 \\
\hline Ampicillin & 0.125 & 0.125 & $0.25->64$ & 2 & $>64$ \\
\hline Ceftriaxone & 0.25 & 0.125 & $0.5->64$ & 1 & $>64$ \\
\hline Cefuroxime & 0.06 & 0.06 & $0.25->64$ & 0.5 & $>64$ \\
\hline Cephalothin & 0.06 & 0.06 & $0.13->64$ & 1 & $>64$ \\
\hline Chloramphenicol & 8 & 8 & $16-32$ & 32 & 32 \\
\hline Ciprofloxacin & 2 & 2 & $4->64$ & $>64$ & $>64$ \\
\hline Clindamycin & 2 & 4 & $0.25->64$ & $>64$ & $>64$ \\
\hline Erythromycin & 0.125 & 8 & $\leq 0.03->64$ & $>64$ & $>64$ \\
\hline Gentamicin & $\leq 0.03$ & 0.125 & $4->64$ & 16 & 32 \\
\hline Imipenem & $\leq 0.03$ & $\leq 0.03$ & $\leq 0.03->64$ & 0.5 & $>64$ \\
\hline Oxacillin & 1 & 0.5 & $2->64$ & 16 & $>64$ \\
\hline Penicillin & 0.06 & 0.06 & $0.25->64$ & 2 & $>64$ \\
\hline Rifampin & $\leq 0.03$ & $\leq 0.03$ & $\leq 0.03->64$ & $>64$ & $>64$ \\
\hline Sparfloxacin & 2 & 4 & $\leq 0.03-32$ & 32 & 32 \\
\hline Teicoplanin & 0.125 & 0.5 & $0.13-0.5$ & 0.5 & 0.5 \\
\hline Tetracycline & 1 & 2 & $0.5-32$ & 1 & 2 \\
\hline Trimethoprim-sulfamethoxazole & 16 & 16 & $>64$ & $>64$ & $>64$ \\
\hline Vancomycin & 0.25 & 0.25 & $0.13-0.5$ & 0.25 & 0.25 \\
\hline
\end{tabular}

${ }^{a}$ Susceptibility to O/129 was determined by the disk diffusion method (see text). The C. xerosis strains were susceptible to O/129 (inhibition zone, 12 to $28 \mathrm{~mm}$ ), and the $C$. amycolatum strains were resistant.

belonged to the species represented by the C.xerosis type strain (ATCC 373). The reference strain ATCC 7711 is a true $C$. xerosis strain, whereas the reference strain NCTC 7243 belongs to $C$. amycolatum.

For the routine clinical laboratory, we recommend use of the following criteria for differentiating between $C$. xerosis and $C$. amycolatum strains: dry, rough colonies of fermentative coryneform bacteria with yellowish pigment should raise the suspicion of $C$. xerosis, whereas $C$. amycolatum exhibits dry colonies which are never pigmented; susceptibility to $\mathrm{O} / 129$ differentiates the susceptible $C$. xerosis strains from the resistant $C$. amycolatum strains; the activity of $\alpha$-glucosidase also provides a clear-cut distinction between $C$. xerosis (positive reaction) and $C$. amycolatum (negative reaction) strains. Further means of differentiation include the detection of major amounts of propionic acid (C. amycolatum) rather than lactic acid (C. xerosis) as an end product of glucose fermentation and assays for the presence (C.xerosis) or absence (C. amycolatum) of mycolic acids. Different $\mathrm{G}+\mathrm{C}$ contents had been reported before for " $C$. xerosis" strains (6), which can now be explained by the fact that $C$. amycolatum strains (55 to $60 \mathrm{~mol} \% \mathrm{G}+\mathrm{C}$ ) have a significantly lower $\mathrm{G}+\mathrm{C}$ content than authentic $C$. xerosis strains (66 to $69 \mathrm{~mol} \%)$. Subtle quantitative $\left(\mathrm{C}_{16: 0}\right.$ and $\mathrm{C}_{18: 1 \omega 9 c i s}$ ) and qualitative (presence [C.xerosis] or absence [C. amycolatum] of poorly cleaved mycolic acids) differences may also assist in the differentiation of these taxa.

In our experience, $C$. xerosis is extremely rarely found in clinical specimens, whereas $C$. amycolatum is probably the most frequently encountered nonlipophilic Corynebacterium species in clinical specimens. Because C. amycolatum is variable for many biochemical reactions such as nitrate reduction, urea hydrolysis, and fermentation of maltose and sucrose (3, 5 ), it seems most likely that many more $C$. amycolatum strains are misidentified as $C$. striatum or $C$. minutissimum, as outlined by Barreau et al. (3). We therefore emphasize that every strain of fermenting coryneform bacteria with dry colonies should raise the suspicion of $C$. amycolatum.

The misidentification of $C$. amycolatum as C. xerosis is al- lowed by the Hollis-Weaver charts (14) (which could not possibly contain C. amycolatum because this species was proposed later by Collins and coworkers [5]) since none of the 33 biochemical features given in the tables separates $C$. amycolatum from $C$. xerosis. The commercial API (RAPID) Coryne system may also misidentify $C$. amycolatum strains as $C$. xerosis (Table 3 ); its database states that only $4 \%$ of all $C$. xerosis strains are $\alpha$-glucosidase positive (1). Therefore, it seems likely that the database for $C$. xerosis was constructed with $C$. amycolatum strains. $\alpha$-Glucosidase activity is a good marker for $C$. xerosis strains because only a few other Corynebacterium species pathogenic for humans $(C$. diphtheriae, $C$. ulcerans, $C$. pseudotuberculosis, and C. glucuronolyticum) exhibit activity of this enzyme, and all of these strains can be readily distinguished from $C$. xerosis $(1,6,10)$. It is important to note that nitrate reduction in authentic $C$. xerosis strains is variable, which is in contrast to the data given both in the Hollis-Weaver charts (14) as well as in the API (RAPID) Coryne database (1).

TABLE 5. Cellular fatty acid patterns of the strains studied

\begin{tabular}{lccc}
\hline \multirow{2}{*}{ Component } & \multicolumn{3}{c}{ \% Cellular fatty acids $(\text { mean } \pm \text { SD [range] })^{a}$} \\
\cline { 2 - 3 } & \multicolumn{2}{c}{ C. xerosis $(n=2)$} & $\begin{array}{c}\text { C. amycolatum } \\
(n=24)^{b}\end{array}$ \\
\cline { 2 - 3 } & ATCC 373 & ATCC 7711 & \\
\hline $\mathrm{C}_{14: 0}$ & 2 & & $1 \pm 1(0-1)$ \\
$\mathrm{C}_{16: 1 \omega 9 \text { cis }}$ & 12 & 1 & $2 \pm 1(1-2)$ \\
$\mathrm{C}_{16: 0}$ & 1 & & $26 \pm 2(24-31)$ \\
$\mathrm{C}_{17: 0}$ & 54 & 2 & $3 \pm 2(1-7)$ \\
Feature $6^{c}$ & 2 & 46 & $2 \pm 1(2-3)$ \\
$\mathrm{C}_{18: 1 \omega 9 \text { cis }}$ & 16 & 2 & $36 \pm 3(33-39)$ \\
${\text { Feature } 7^{d}}_{\mathrm{C}_{18: 0}}$ & 27 & $29 \pm 1(0-2)$ \\
\hline
\end{tabular}

${ }^{a}$ Amounts of less than $1 \%$ were not reported.

${ }^{b}$ Two of the 26 C. amycolatum strains were not included in this analysis.

${ }^{c}$ Feature 6 contains $\mathrm{C}_{18: 2 \omega 6 \text { cis }}, \mathrm{C}_{18: 2 \omega 9 \text { cis }}$, and $\mathrm{C}_{18: 0 a n t e i s o}$.

${ }^{d}$ Feature 7 contains $\mathrm{C}_{18: 1 \omega 7 \text { cis }}, \mathrm{C}_{18: 1 \omega 9 \text { trans }}$, and $\mathrm{C}_{18: 1 \omega 12 \text { trans }}$. 
Coyle et al. (7) assigned 3 of the 10 "C. xerosis" reference strains examined in their study to the species $C$. striatum, 4 of the 10 strains belonged to some lipophilic Corynebacterium species $(7,17)$, and this report demonstrated that strain NCTC 7243 is $C$. amycolatum. In contrast to our results, Coyle et al. (7) assigned strains ATCC 373 and ATCC 7711 to different hybridization groups, i.e., separate species. However, our data indicating $100 \%$ homology within the 16S rRNA genes of both strains demonstrate that they most likely belong to the same species. The reason for this discrepancy is unclear. Profiles of whole-cell protein electrophoresis as well as the mycolic acid patterns were almost identical for strains ATCC 373 and ATCC 7711, thereby reinforcing the close relation between the two strains $(8,15)$.

Like $C$. jeikeium and $C$. urealyticum, many $C$. amycolatum strains are resistant to multiple antibiotics. The molecular basis for this feature of $C$. amycolatum strains is not known at present. Nearly all multiresistant $C$. amycolatum strains remained susceptible to tetracycline, an observation that was also reported by Soriano et al. (25) for their so-called $C$. xerosis strains.

We conclude that the majority of strains designated " $C$. xerosis" in the literature may have been, in fact, misidentified C. amycolatum strains. True C. xerosis strains are, in our experience, extremely rarely encountered in clinical specimens. Therefore, for future publications on $C$. xerosis, performance of the minimal set of tests outlined above seems to be necessary to ensure the identity of the tested strains as authentic $C$. xerosis strains.

\section{ACKNOWLEDGMENTS}

We recognize A. von Graevenitz for an early awareness of the problem and for a careful review of the manuscript. V. Pünter and J. Winstanley provided expert technical assistance.

This study was supported by the European Community (CT93-0119 and CT94-3098), the Jubiläumsspende der Universität Zürich, and the Hochschulverein Zürich. G.F. acknowledges support by a grant from the Sassella-Stiftung (Zürich, Switzerland).

\section{REFERENCES}

1. API. 1989. API CORYNE analytical profile index, 1st ed. API System, La-Balme-les-Grottes, France.

2. Arisoy, E. S., G. J. Demmler, and W. M. Dunne, Jr. 1993. Corynebacterium xerosis ventriculoperitoneal shunt infection in an infant: report of a case and review of the literature. Pediatr. Infect. Dis. J. 12:536-538.

3. Barreau, C., F. Bimet, M. Kiredjian, N. Rouillon, and C. Bizet. 1993. Comparative chemotaxonomic studies of mycolic acid-free coryneform bacteria of human origin. J. Clin. Microbiol. 31:2085-2090.

4. Bernard, K. A., M. Bellefeuille, and E. P. Ewan. 1991. Cellular fatty acid composition as an adjunct to the identification of asporogenous, aerobic gram-positive rods. J. Clin. Microbiol. 29:83-89.

5. Collins, M. D., R. A. Burton, and D. Jones. 1988. Corynebacterium amycolatum sp. nov. a new mycolic acid-less Corynebacterium species from human skin. FEMS Microbiol. Lett. 49:349-352.

6. Collins, M. D., and C. S. Cummins. 1986. Genus Corynebacterium, p. 12661276. In P. H. A. Sneath, N. S. Mair, M. E. Sharpe, and J. G. Holt (ed.), Bergey's manual of systematic bacteriology, vol. 2. The Williams \& Wilkins Co., Baltimore.
7. Coyle, M. B., R. B. Leonard, D. J. Nowowiejski, A. Malekniazi, and D. J. Finn. 1993. Evidence of multiple taxa within commercially available reference strains of Corynebacterium xerosis. J. Clin. Microbiol. 31:1788-1793.

8. De Briel, D., F. Couderc, P. Riegel, F. Jehl, and R. Minck. 1992. Highperformance liquid chromatography of corynomycolic acids as a tool in identification of Corynebacterium species and related organisms. J. Clin. Microbiol. 30:1407-1417.

9. Devereux, J., P. Haeberli, and O. Smithies. 1984. A comprehensive set of sequence analysis programs for the VAX. Nucleic Acids Res. 12:387-395.

10. Funke, G. K. A. Bernard, C. Bucher, G. E. Pfyffer, and M. D. Collins. 1995. Corynebacterium glucuronolyticum sp. nov. isolated from male patients with genitourinary infections. Med. Microbiol. Lett. 4:205-215.

11. Funke, G., G. Martinetti Lucchini, G. E. Pfyffer, M. Marchiani, and A. von Graevenitz. 1993. Characteristics of CDC group 1 and group 1-like coryneform bacteria isolated from clinical specimens. J. Clin. Microbiol. 31:29072912.

12. Funke, G., C. Pascual Ramos, and M. D. Collins. 1995. Identification of some clinical strains of CDC coryneform group A-3 and A-4 bacteria as Cellulomonas species and proposal of Cellulomonas hominis sp. nov. for some group A-3 strains. J. Clin. Microbiol. 33:2091-2097.

13. Gaskin, P. R. A., M. A. St John, C. T. Cave, H. Clarke, R. Bayston, and P. N. Levett. 1994. Cerebrospinal fluid shunt infection due to Corynebacterium xerosis. J. Infect. 28:323-325.

14. Hollis, D. G., and R. E. Weaver. 1981. Gram-positive organisms: a guide to identification. Special Bacteriology Section, Centers for Disease Control, Atlanta.

15. Jackman, P. J. H. 1982. Classification of Corynebacterium species from axillary skin by numerical analysis of electrophoretic protein patterns. J. Med. Microbiol. 15:485-492.

16. King, C. T. 1994. Sternal wound infection due to Corynebacterium xerosis. Clin. Infect. Dis. 19:1171-1172.

17. Lawson, P. A., and M. D. Collins. Unpublished data

18. Lortholary, O., A. Buu-Hoi, J. Y. Fagon, J. Pierre, M. Slama, L. Gutmann, and J. F. Acar. 1993. Mediastinitis due to multiply resistant Corynebacterium xerosis. Clin. Infect. Dis. 16:172.

19. Malik, A. S., and M. R. Johari. 1995. Pneumonia, pericarditis, and endocarditis in a child with Corynebacterium xerosis septicemia. Clin. Infect. Dis 20:191-192.

20. Nash, P., and M. M. Krenz. 1991. Culture media, p. 1226-1288. In A. Balows, W. J. Hausler, Jr., K. L. Hermann, H. D. Isenberg, and H. J. Shadomy (ed.), Manual of clinical microbiology, 5th ed. American Society for Microbiology, Washington, D.C.

21. National Committee for Clinical Laboratory Standards. 1993. Methods for dilution antimicrobial susceptibility tests for bacteria that grow aerobically, 3rd ed. Approved standard. NCCLS document M7-A-3. National Committee for Clinical Laboratory Standards, Villanova, $\mathrm{Pa}$.

22. National Committee for Clinical Laboratory Standards. 1993. Minimum inhibitory concentration (MIC) interpretive standards $(\mu \mathrm{g} / \mathrm{ml})$ for organisms other than Haemophilus, Neisseria gonorrhoeae, and Streptococcus pneumoniae. NCCLS document M7-A3. National Committee for Clinical Laboratory Standards, Villanova, $\mathrm{Pa}$.

23. Pascual, C., P. A. Lawson, J. A. E. Farrow, M. Navarro Gimenez, and M. D. Collins. 1995. Phylogenetic analysis of the genus Corynebacterium based on $16 \mathrm{~S}$ rRNA gene sequences. Int. J. Syst. Bacteriol. 45:724-728.

24. Schaal, K. P. 1985. Identification of clinically significant actinomycetes and related bacteria using chemical techniques, p. 359-381. In M. Goodfellow and D. E. Minnikin (ed.), Chemical methods in bacterial systematics. Academic Press, London.

25. Soriano, F. J. Zapardiel, and E. Nieto. 1995. Antimicrobial susceptibilitie of Corynebacterium species and other non-spore-forming gram-positive bacilli to 18 antimicrobial agents. Antimicrob. Agents Chemother. 39:208-214

26. Vettese, T. E., and C. P. Craig. 1993. Spontaneous bacterial peritonitis due to Corynebacterium xerosis. Clin. Infect. Dis. 17:815.

27. Wallet, F., C. H. Marquette, and R. J. Courcol. 1994. Multiresistant Corynebacterium xerosis as a cause of pneumonia in a patient with acute leukemia. Clin. Infect. Dis. 18:845-846.

28. Wood, C. A. 1993 . Nosocomial infection of a pancreatic pseudocyst due to Corynebacterium xerosis. Clin. Infect. Dis. 17:934-935. 